\title{
Influence of the Cooling Rate of Silica Glass on Its Surface Relief
}

\author{
Peter Parfenov ${ }^{1}$ and Mikhail Eronyan ${ }^{1,2 *}$ \\ ${ }^{1}$ ITMO University, Russia \\ ${ }^{2}$ JSC Concern Central Research Institute Elektropribor, Russia
}

*Corresponding author: Mikhail Eronyan, Laboratory of optical fibers JSC Concern Central Research Institute Elektropribor, St. Petersburg, Russia

To Cite This Article: Peter Parfenov, Mikhail Eronyan. Influence of the Cooling Rate of Silica Glass on Its Surface Relief. Am J Biomed Sci \& Res. 2021 - 13(3). AJBSR.MS.ID.001879. DOI: 10.34297/AJBSR.2021.13.001879.

Received: 觜 April 18, 2021; Published: 阱 July 06, 2021

\begin{abstract}
The method of atomic force microscopy explores a roughness of a surface of the silica glass cooled with different velocity from temperature 2300 ${ }^{\circ} \mathrm{C}$. It is compared two modes of cooling of a glass rods with a diameter of $16 \mathrm{~mm}$ : convective heat exchange with the surrounding air and quenching with dropping the sample into a vessel with water. The roughness of a surface of a silica glass in the second mode of cooling was essentially less that can promote magnification of its strength. The results of these studies may turn out to be promising in terms of increasing the strength and reliability of silica optical fibers used in laser surgery.
\end{abstract}

Keywords: Silica glass; Strength; Roughness; Laser surgery

\section{Introduction}

The silica glass (SG) possesses high strength, which is estimated to be equal to 22-44GPa [1]. Experimental studies on ultra-thin fibers made of SG with a diameter of $120 \mathrm{~nm}$ [2] showed strength close to the theoretical level (26GPa). This result, along with the small size of the tested fiber sample, can also be due to its high cooling rate, which helps to reduce the surface roughness of the SG.

Strength of silica fibers with a diameter of $125 \mathrm{~mm}$ is equal to $6 \mathrm{GPa}$. It is determined by surface defects of $6 \mathrm{~nm}$ in size, which can arise due to the processes of liquation and segregation in the presence of trace impurities [3] or crystallization of glass [4]. An increase in the cooling rate of the SG can counteract the indicated defect formation processes. However, the roughness of the glass surface due to the formation of a globular structure [5] can also affect its strength properties. Globules are formed in glass at a relatively low viscosity and higher temperatures compared to the processes of liquation, segregation, and crystallization. Until now, the effect of the cooling rate of the SG on the relief of its surface has not been studied. Purpose of this work was to fill this knowledge gap by studying the effect of the cooling rate of the SG on the roughness of its surface, measured by atomic force microscopy (AFM).

\section{Material and Methods}

In the experiment's rods made of $\mathrm{F}$ 300SG with a diameter of $16 \mathrm{~mm}$ were used. The rod rotating at a speed of $45 \mathrm{rpm}$ was heated by the flame of an oxygen-hydrogen burner using an Nextrom's automated OFC-12-729 system equipped with an IR pyrometer to measure the temperature of the SG.

After reaching the maximum possible temperature $\left(2300{ }^{\circ} \mathrm{C}\right)$, the burner was turned off. The samples were cooled down under two different conditions:

- Convective heat exchange with the surrounding air and

- $\quad$ Quenching with dropping the sample for 1 second into a vessel with water.

The sample surface relief was analyzed using an AFM grade Solver PRO-M. The study was performed in the contact mode using 
an NSG01 probe with a radius of the nip curve of 10nm, which provided a horizontal resolution of up to $20 \mathrm{~nm}$ and a vertical resolution of less than $0.1 \mathrm{~nm}$.

\section{Results and Discussion}

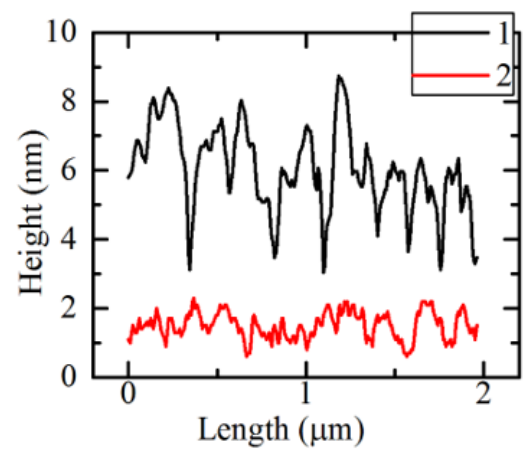

Figure 1: Sample roughness for the first (above line) and second (below line) cooling modes.

The results of measurements of the relief of the SG showed that the roughness of the water quenched sample was significantly lower than that of the sample that was left cooling down surrounded by ambient air (Figure 1). Taking into the account the different scales of the vertical and horizontal axes, the real relief of the sample surface is relatively flat. The roughness level of the glass measured here likely correlates with the presence of the small fractures detrimental for the glass strength. It also should be noted that the resolution of the cantilever does not reveal any narrow fractures with a width $<10 \mathrm{~nm}$.

\section{Conclusion}

The results of these studies may turn out to be promising in terms of increasing the strength and reliability of silica optical fibers used in laser surgery.

\section{References}

1. Wiederhorn SM (1969) Fracture surface energy of glass. Amer Ceram Soc 52(2): 99-105.

2. Brambilla G, Payne DN (2009) The ultimate strength of glass silica nanowires. Nano Lett 9(2): 831-835.

3. Eronyan MA, Zlobin PA, Kozlova MA, Levit LG, Romashova EI, et al. (2006) Influence of the physicochemical state of impurities on the strength of silica fibers. Glass Phys Chem 32(6): 623-628.

4. Kulesh A, Eronyan M, Meshkovskii I, Zolotarev V, Bisyarin M, et al. (2015) Crystallization of quartz glass fibers during the drawing process. Crystal Growth \& Design 15(6): 2831-2834.

5. Dolapchi SM, Denisova OA (2017) Globules and their internal structure. Elektrotekh Inform Kompleksy Sist 13(2): 106-111. 